\title{
PERFIL CLÍNICO EPIDEMIOLÓGICO E PREVALÊNCIA DE FADIGA EM PESSOAS COM DOENÇA FALCIFORME EM FEIRA DE SANTANA
}

\author{
Heros Aureliano Antunes da Silva Maia ${ }^{1}$; Evanilda Souza de Santana Carvalho²; \\ José de Bessa Júnior ${ }^{3}$ e Mateus Andrade Alvaia ${ }^{4}$ \\ 1. Bolsista PIBIC/CNPq, Graduando em Medicina, Universidade Estadual de Feira de Santana, e-mail: \\ herosmaia@hotmail.com \\ 2. Orientadora, Departamento de Saúde, Universidade Estadual de Feira de Santana, e-mail: \\ evasscarvalho@yahoo.com.br \\ 3. Co-Orientador, Participante do Núcleo Urologia/Saúde de Subgrupos, Departamento de Saúde, Universidade \\ Estadual de Feira de Santana, e-mail: josedebessa@gmail.com \\ 4. Participante do Núcleo Urologia/Saúde de Subgrupos, Departamento de Saúde, Universidade Estadual de Feira de \\ Santana, e-mail: mateus_alvaia@hotmail.com
}

PALAVRAS-CHAVE: Doença Falciforme; Fadiga; Perfil de Saúde.

\section{INTRODUÇÃO}

A doença falciforme (DF) é uma das doenças hereditárias mais prevalentes no mundo. No Brasil, sua inserção está relacionada a composição afrodescendente da população. O estado da Bahia possui a maior incidência da DF no país: 1:650 nascidos vivos e 1:17 com traço falciforme (CORDEIRO et al, 2014).

A fisiopatologia da DF advém de mutação no gene da $\beta$-globina, que culmina na hemoglobina $\mathrm{S}(\mathrm{HbS})$, promotora de rigidez eritrocitária, hemólise, hipóxia e inflamação (LOVETT et al, 2014), responsáveis pelas manifestações clínicas e complicações da doença: crises álgicas, síndrome torácica aguda, priapismo, sequestro esplênico, entre outras.

Dentre as manifestações, encontra-se a fadiga, fenômeno subjetivo e multifatorial, entendida como sensação física desagradável, com componentes cognitivos e emocionais, descrita como cansaço não aliviado por estratégias usuais de restauração de energia (ABCP, 2010).

A fadiga é um dos sintomas mais comuns, mas pouco se sabe sobre sua prevalência, intensidade e impacto (AMERINGER et al, 2014). Há uma lacuna na literatura sobre essa temática no cenário da DF. O presente estudo busca 1) Estimar a prevalência de fadiga, sua intensidade e impacto na vida diária, 2) Descrever o perfil sociodemográfico e clínico, 3) Verificar a associação de fatores sociodemográficos e clínicos com a fadiga em pessoas com DF em Feira de Santana (FSA), Bahia.

\section{METODOLOGIA}

Estudo transversal, exploratório e descritivo, realizado no Centro de Referência em Doença Falciforme, em FSA. Participaram pessoas com DF acima de 16 anos mediante assinatura de Termo de Consentimento Livre e Esclarecido; obteve-se assinatura dos responsáveis legais dos menores de 18 anos. Estudo aprovado pelo Comitê de Ética em Pesquisa da Universidade Estadual de Feira de Santana (parecer $\mathrm{n}^{\mathrm{o}}$ 5269/2013).

Para caracterização sociodemográfica e clínica, utilizou-se questionário elaborado pelos autores. Adotou-se os critérios para gravidade da DF de Martyres e colaboradores (2016). Para estimar a prevalência de fadiga, utilizou-se perguntas 
referenciais teóricas da fadiga associada a Escala Numérica da Fadiga, abordagem preconizada no Consenso Brasileiro de Fadiga (ABCP, 2010). A intensidade e impacto da fadiga nas atividades de vida diária foram avaliadas a partir do Pictograma da Fadiga (ABCP, 2010).

A partir dos dados coletados, foi realizada análise descritiva. A associação entre os parâmetros estudados foi expressa pela razão de prevalência ou Odds Ratio. Intervalos de confiança de $95 \%$ foram empregados como medidas de precisão dos resultados. Valores de $\mathrm{p}$ menores que $0,05(\mathrm{p}<0,05)$ foram considerados significativos. Nas análises foi utilizado o programa estatístico computacional GraphPad Prism, versão 6.0.3, GraphPad Software, San Diego-CA, USA.

\section{RESULTADOS E DISCUSSÃO}

Participaram 71 pacientes, com idade média de 34,27士11,52 anos, dos quais 54,92\% mulheres, $95,77 \%$ pretos e pardos, 35,21\% com ensino médio completo, $78,87 \%$ desempregados, $57,74 \%$ solteiros e 78,87\% com renda familiar $\leq 1$ salário mínimo. Em relação aos hábitos de vida, 95,77\% não tabagistas, $85,91 \%$ não etilistas, $77,46 \%$ sedentários, $43,67 \%$ seguiam dieta alimentar orientada por nutricionista, $74,64 \%$ estavam com calendário vacinal atualizado, 71,84\% não usavam hidroxiureia e todos utilizavam ácido fólico.

Maior parte dos pacientes era $\mathrm{HbSS}(53,52 \%), 45,07 \% \mathrm{HbSC}$ e 1,4\% HbS $\beta$ thal; $76 \%$ buscaram os serviços de urgência/emergência e 60\% sofreram internações hospitalares no último ano. As complicações mais frequentes foram: crises álgicas $(74,64 \%)$, síndrome torácica aguda $(43,66 \%)$, colecistite $(40,84 \%)$, retinopatia $(36,61 \%)$, necrose de cabeça de fêmur $(16,9 \%)$, úlcera de perna $(16,9 \%)$, priapismo $(15,49 \%)$ e sequestro esplênico $(15,49 \%)$.

Tal perfil sociodemográfico e clínico é similar ao encontrado em outros estudos epidemiológicos em território nacional (FELIX et al, 2010, SANT'ANA et al, 2017). Antes considerada uma doença fatal da infância, atualmente a DF é encarada como doença crônica; o aumento da expectativa de vida se deve aos avanços no diagnóstico precoce e tratamento regular da doença, com folato, penicilina profilática, hidroxiureia e vacinação adicional (JENERETTE et al, 2011), além de outras medidas de estilo de vida saudável.

Quanto à gravidade da DF: 71,83\% eram graves, $18,3 \%$ moderados e 9,85\% leves. Pacientes homozigóticos apresentaram formas mais graves da DF ( $\mathrm{p}=0,066$, Odds Ratio $=2,88[1,01-7,89]$ IC95\%). O genótipo HbSS geralmente é reconhecido como mais grave, contudo, mesmo entre um genótipo há grande variabilidade clínica individual, de forma que vários estudos tentaram classificar a gravidade combinando manifestações clínicas agudas, complicações crônicas e resultados laboratoriais, mas ainda insuficientes para predizer desfechos adversos globais (QUINN, 2016).

Constatou-se fadiga em 19/71 sujeitos, prevalência de 26,76\% [17,79 - 38,12\%] IC95\%. Não houve correlação significativa entre fadiga e idade $(\mathrm{p}=0,14)$, genótipo SS $(\mathrm{p}=0,18)$, sexo $(\mathrm{p}=0,43)$, gravidade da $\mathrm{DF}(\mathrm{p}=0,55)$ e uso de hidroxiureia $(\mathrm{p}=0,23)$. A fadiga foi mais frequente que a necrose de cabeça de fêmur e úlcera de perna. A prevalência de fadiga encontrada no presente estudo é similar com a fadiga em outras 
condições crônicas: câncer colorretal (26,8\%) (MOTA et al, 2012) e dor lombar crônica (26\%) (SALVETTI et al, 2013), todos estudos utilizaram a Escala de Fadiga de Piper.

Em estudo no Irã, ao usar a Escala de Severidade da Fadiga, encontrou-se fadiga em $65 \%$ dos indivíduos com DF, também sem associação significativa com características demográficas e individuais (AHMADI et al, 2018). Diferenças metodológicas de mensuração da fadiga podem explicar a diferença na prevalência de fadiga em comparação com o presente estudo, o que reafirma a dificuldade de mensuração e o caráter multidimensional desse sintoma.

A despeito da não associação da fadiga com variáveis como gravidade da doença, idade e citocinas, parece bem estabelecido na literatura a relação de fadiga na DF e fatores comportamentais como sono, dor, ansiedade e depressão (AMERINGER et al, 2014; AHMADI et al, 2018).

No grupo dos fatigados, a intensidade da fadiga foi grave em $42,1 \%$ e extrema em 21,05\%; o impacto nas atividades diárias foi moderado em 47,36\% e grave em 26,31\%. A questão 2 do Pictograma da Fadiga, referente ao impacto da fadiga nas atividades diárias, indicou diferença significativa entre os fatigados e os não fatigados $(\mathrm{p}=0,0031$, Odds Ratio = 0,1487 [0,0426 - 0,5417] IC95\%).

Os resultados do pictograma da fadiga apontaram que a intensidade da fadiga foi maior que seu impacto nas atividades diárias. Comparativamente, em pacientes com câncer, 41,8\% apontaram intensidade de fadiga moderada ou superior e 38,3\% apontaram impacto moderado ou superior (MOTA et al, 2009). A DF é uma condição crônica, presente desde o nascimento, de forma que é possível que as pessoas com DF desenvolvam mecanismos comportamentais para enfrentar a fadiga.

\section{CONCLUSÕES}

O estudo revelou que o perfil sociodemográfico dos pacientes atendidos no CRDF, em Feira de Santana, é predominantemente de mulheres jovens, negras, solteiras, de baixa renda familiar e homozigotas SS. As manifestações mais frequentes foram as crises álgicas, síndrome torácica aguda, colecistite, retinopatia falciforme e priapismo. Maioria dos pacientes possuem DF grave; gravidade com associação significativa com genótipo $\mathrm{HbSS}$.

A prevalência de fadiga foi de $26,76 \%$, superior à prevalência de necrose de cabeça de fêmur e úlcera de perna na população estudada e comparável à existente em outras condições crônicas. Não houve associação da fadiga com nenhuma variável sociodemográfica e clínica. A intensidade da fadiga é maior que seu impacto nas atividades diárias na DF, o que pode sugerir desenvolvimento de mecanismos intrínsecos de enfrentamento.

O presente estudo reafirma a dificuldade em se mensurar a fadiga: há múltiplas escalas para sua mensuração, o que limita a validade de comparação entre diferentes populações. Sugere-se o desenvolvimento de novas escalas e instrumentos de mensuração específicos para a DF ou adoção de novos pontos de corte nas escalas existentes para estudos futuros. É necessário estabelecer avaliação clínica de rotina da fadiga em pessoas com DF, além de se buscar intervenções eficazes para seu manejo, no contexto do cuidado multidisciplinar. 
Quanto às limitações do estudo, destacam-se o tamanho reduzido da amostra, o que limita a generalização dos achados, além da não mensuração dos parâmetros hematológicos. Ademais, não foi incluído um grupo controle saudável para comparação dos níveis de fadiga.

\section{REFERÊNCIAS}

AHMADI, M.; POORMANSOURI, S.; BEIRANVAND, S.; SEDIGHIE, L. Predictors and correlates of fatigue in sickle cell disease patients. International Journal of Hematology-Oncology and Stem Cell Research, v. 12, n. 1, p. 69-76, jan. 2018.

AMERINGER, S.; ELSWICK, R. K.; SMITH, W. Fatigue in Adolescents and Young Adults With Sickle Cell Disease. Journal of Pediatric Oncology Nursing, v. 31, n. 1, p. 6-17, jan-fev. 2014.

ASSOCIAÇÃO BRASILEIRA DE CUIDADOS PALIATIVOS (ABCP). Consenso brasileiro de fadiga. Revista Brasileira de Cuidados Paliativos, São Paulo, v.3, n. 2, suplemento 1, 2010.

CORDEIRO, R. C.; FERREIRA, S. L.; SANTOS, A. C. DA C. Experiências do adoecimento de pessoas com anemia falciforme e estratégias de autocuidado. ACTA Paulista de Enfermagem, v. 27, n. 6, p. 499-504, dez. 2014.

FELIX, A. A.; SOUZA, H. M.; RIBEIRO, S. B. F. Aspectos epidemiológicos e sociais da doença falciforme. Revista Brasileira de Hematologia e Hemoterapia, v. 32, n. 3, p. 203-208, 2010.

JENERETTE, C. M.; BREWER, C.; LEAK, A. N. Self-Care Recommendations of Middle-Aged and Older Adults with Sickle Cell Disease. Nursing Research and Practice, v. 2011, p. 1-5, 2011.

LOVETT, P. B. et al. Sickle cell disease in the emergency department. Emerg Med Clin N Am. Vol. 32, n. 3, p. 629-47, ago. 2014.

MARTYRES, D.; VIJENTHIRA, A.; BARROWMAN, N.; et al. Nutrient Insufficiencies/Deficiencies in Children With Sickle Cell Disease and Its Association With Increased Disease Severity. Pediatric Blood Cancer, v. 53, n. December 2008, p. 13-16, jun. 2016.

MOTA, D. D. C. F.; PIMENTA, C. A. M.; CAPONERO, R. Fadiga em pacientes com câncer colorretal: prevalência e fatores associados. Revista Latino Americana de Enfermagem, v. 20, n. 3, p. 1-9, 2012.

MOTA, D. D. C. F.; PIMENTA, C. A. M.; FITCH, M. I. Pictograma de Fadiga: uma alternativa para avaliação da intensidade e impacto da fadiga. Revista da Escola de Enfermagem da USP, v. 43, n. spe, p. 1080-1087, 2009.

QUINN, C. T. Minireview: Clinical severity in sickle cell disease: the challenges of definition and prognostication. Experimental Biology and Medicine, v. 241, n. 7, p. 679-688, 2016.

SAlVETTI, M. D. G.; PIMENTA, C. A. D. M.; BRAGA, P. E.; MCGILliON, M. Prevalência de fadiga e fatores relacionados em pacientes com dor lombar crônica. Rev Latino-Am Enfermagem, v. 21, p. 1-8, 2013.

SANT'ANA, P. G. S.; ARAÚJO, A. M.; PIMENTA, C. T.; et al. Clinical and laboratory profile of patients with sickle cell anemia. Revista Brasileira de Hematologia e Hemoterapia, v. 39, n. 1, p. 40-45, 2017. 